\title{
Differentiating between non-functioning pituitary macroadenomas and sellar meningiomas using ADC
}

\author{
Jing Zhang ${ }^{1,2,3, *}$, Zhiyong Zhao 1,2,3,*, Li Dong4,*, Tao Han ${ }^{1,2,3}$, Guojin Zhang ${ }^{1,2,3}$, Yuntai Cao ${ }^{1,2,3}$ and Junlin Zhou(1,2,3 \\ ${ }^{1}$ Department of Radiology, Lanzhou University Second Hospital, Lanzhou, China \\ ${ }^{2}$ Key Laboratory of Medical Imaging of Gansu Province, Lanzhou, China \\ ${ }^{3}$ Second Clinical School, Lanzhou University, Lanzhou, China \\ ${ }^{4}$ Department of Pathology, Lanzhou University Second Hospital, Lanzhou, China \\ Correspondence should be addressed to J Zhou: ery_zhoujl@Izu.edu.cn
}

*(J Zhang, Z Zhao and L Dong contributed equally to this work)

\begin{abstract}
Introduction and aim: It is difficult to distinguish between non-functioning pituitary macroadenomas (NFPMAs) and sellar meningiomas because of their overlapping imaging manifestations on routine MRI, especially in cases of meningiomas growing into the saddle. Here, we aimed to differentiate between these two tumors using apparent diffusion coefficient (ADC) values and MRI characteristics.

Methods: A total of 60 NFPMA and 52 sellar meningioma cases confirmed by the pathological analysis were retrospectively reviewed. All patients were examined via routine MRI and diffusion-weighted imaging (DWI) before undergoing surgery. The clinical characteristics, MRI characteristics, and max ADC (ADCmax), average ADC (ADCmean), and minimum ADC (ADCmin) values were compared between the two tumors via Chi-square test and two sample t-tests. Receiver operating characteristic (ROC) curve and binary logistic regression analyses were conducted to determine the discrimination ability.

Results: The ADCmax, $A D C$ mean, and $A D C$ min values were significantly higher in NFPMAs compared to sellar meningiomas ( $P<0.001$ for all). Among ADC values, ADCmax demonstrated good performance with an AUC of 0.896 ( $95 \% \mathrm{Cl}, 0.823-0.969)$ and accuracy of $88.7 \%$. A cut-off value of $0.97 \times 10^{-3} \mathrm{~mm}^{2} / \mathrm{s}$ was used for $A D C m a x$ for differentiation between tumors. A combination of $A D C m a x$ values and clinicoradiological features showed the best discrimination ability for differential diagnosis between the two tumors, with an AUC of 0.981 (95\% Cl, 0.958-1.000) and accuracy of $96.9 \%$. Conclusion: A combination of ADCmax and clinicoradiological features demonstrates good discrimination ability and high accuracy for differentiation between NFPMAs and sellar meningiomas, and is a potential quantitative tool to aid in the selection of surgical techniques.
\end{abstract}

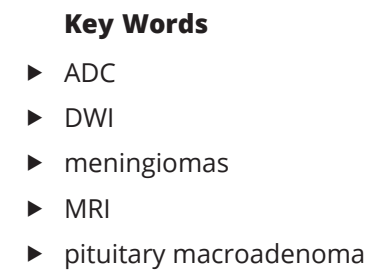

Endocrine Connections (2020) 9, 1233-1239

\section{Introduction}

Pituitary adenomas and meningiomas are the most common benign tumors in the CNS (1). Pituitary adenomas arise from the pituitary gland and account for
$10-15 \%$ of all intracranial tumors $(2,3)$. Non-functioning pituitary adenomas account for $14-54 \%$ of pituitary adenomas and lack biochemical evidence of hormone 
secretion (4). Tumors with a diameter of greater than or equal to $10 \mathrm{~mm}$ are considered macroadenomas (2). In contrast, sellar meningiomas arise from adjacent dural surfaces, including the dura surrounding the pituitary fossa, diaphragm sellae, and sella turcica, and represent approximately $5-10 \%$ of all cranial meningiomas (5). When suprasellar or parasellar meningiomas grow downward into the pituitary fossa, which is particularly observed in combined tuberculum and diaphragm sellae meningiomas (Type B) (6) and pituitary macroadenomas that arise within the sella turcica and extended superiorly, differential diagnosis via routine MRI becomes difficult $(5,7)$. However, precise preoperative distinction between these two tumors may aid the determination of a suitable surgical planning. Most sellar meningiomas may require a craniotomy and Dzhindzhikhadze et al., have reported that a transpalpebral approach may be followed, whereas most supra- and intrasellar macroadenomas are resected via the trans-sphenoidal route $(8,9,10,11)$.

Currently, some studies have reported on the identification of these two tumors with traditional methods (e.g., CT and MRI) $(5,8,12)$. Wu et al. (12) reported that quantitative dual-energy CT imaging, iodine content, slope of HU curve, and mean CT value may be valuable parameters for diagnostic differentiation between sellar meningiomas and pituitary adenomas. MRI was mainly performed as the examination of choice for the diagnosis of sellar lesions (13). Some MRI characteristics, such as visibility of the pituitary gland, contrast enhancement, and sellar enlargement can help differentiate pituitary macroadenomas from sellar meningiomas (8). However, the aforementioned methods sometimes may not lead to a confirmed etiological diagnosis because of the uncertainty of the origin of a lesion (13). Diffusion-weighted imaging (DWI) can noninvasively provide information concerning high signal-intensity regions as areas of increased cellularity and tissue microstructures by measuring water diffusion within a tissue $(14,15,16)$, which is closely associated with membrane integrity and cell density (15, 17). The diffusion of water molecules is determined by a high cellularity, a small extracellular space, and a high nuclear-to-cytoplasmic ratio (18). The apparent diffusion coefficient (ADC) is a parameter that is derived from DWI, and represents the average diffusion for each voxel. Accordingly, the ADC values in brain tumors inversely associated with cellularity and the ratio of nuclear area to cytoplasm (18). Previous studies have reported that the ADC value or ratio plays an important role in the differentiation of brain tumors, including benign and atypical/malignant meningiomas and solitary fibrous tumors/hemangiopericytomas and meningiomas $(16,19$, $20,21)$. However, few studies have assessed the role of ADC in the differentiation of non-functioning pituitary macroadenomas (NFPMAs) from sellar meningiomas.

Therefore, in this study, we compared the clinical and MRI characteristics and ADC values between NFPMAs and sellar meningiomas, and determined whether ADC values can improve the diagnostic accuracy of these two tumors.

\section{Materials and methods}

\section{Patients}

For this retrospective analysis, ethical approval was obtained from the Institutional Review Board of Lanzhou University Second Hospital (Lanzhou, China), and the need for informed consent was waived. We analyzed 60 patients with NFPMAs (24 females and 36 males; age, $52.6 \pm 11.2$ years) and 52 patients with sellar meningiomas (43 females and 9 males; age, $52.3 \pm 8.53$ years) confirmed surgically and pathologically at our institute between January 2014 and December 2019. All patients were consecutively admitted to the hospital and underwent routine MRI and DWI within one week before surgery, The images of each patient were of good quality and without artifacts. Patients showing grossly macrocystic and/or hemorrhagic changes ( $n=5$ in the NFPMA group) on measuring ADC values and those for whom ADC values could not be measured $(n=3$ in the NFPMA group and $n=7$ in the sellar meningioma group) because of airtissue interface artifacts were excluded. Accordingly, ADC values of 52 patients with NFPMAs and 45 patients with sellar meningiomas were measured. In all, there were 65 cases of reduced vision, 21 cases of blurred vision, 13 cases of headache and dizziness, 4 cases of epilepsy, and 9 cases of other manifestations.

\section{Imaging protocol}

In this study, the Siemens Verio 3.0 T superconducting MR scanner (Germany) was used, and 112 patients underwent T1WI, T2WI, DWI, and contrast-enhance MRI before surgery. The parameters for MRI included the following: T1WI (TR/TE $=550 / 11 \mathrm{~ms})$, slice thickness $=5.0$ $\mathrm{mm}$, layer spacing $1.5 \mathrm{~mm}$, matrix $=256 \times 256$, field of view $(\mathrm{FOV})=260 \mathrm{~mm} \times 260 \mathrm{~mm}$; T2WI $(\mathrm{TR} / \mathrm{TE}=2200 / 96$ $\mathrm{ms})$, echo chain length $=8$, and number of excitation $(\mathrm{NEX})=2$. The parameters for DWI (SEEPI sequence) were as follows: frequency selection fat suppression technology,

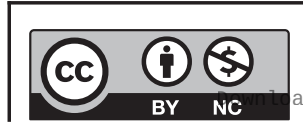

This work is licensed under a Creative Commons Attribution-NonCommercial 4.0 International License. Aed from Bioscientifica.com at 04/26/2023 12:11:32PM 
$(\mathrm{TR} / \mathrm{TE}=4000 / 100 \mathrm{~ms})$, slice thickness $=5 \mathrm{~mm}$, layer spacing $1.5 \mathrm{~mm}$, matrix $=256 \times 192, \mathrm{FOV}=260 \mathrm{~mm} \times 260$ $\mathrm{mm}$, and diffusion gradients applied in three orthogonal directions ( $b$ value $=0,1000 \mathrm{~s} / \mathrm{mm}^{2}$ ). Axial, sagittal, and coronary enhanced T1WI were obtained using Gd-DTPA (Bayer Schering Pharma AG) at $0.1 \mathrm{mmol} / \mathrm{kg}$ at a rate of $3.0 \mathrm{~mL} / \mathrm{s}$.

\section{Image analysis and processing}

Two neuroradiologists (readers 1 and 2, with 12 and 15 years of experience in brain MRI diagnosis, respectively) blindly evaluated the patients data twice within 15 days. In case of a difference in opinions, agreements were reached after discussion between the two. MRI characteristics including maximal diameter, T2W signal, enhancement features, hemorrhage/cyst/necrosis-related changes, DWI signal, sella enlargement, dural tail sign, waist sign (the core of the tumor is thinner than the sides), carotid artery encircling, depression of saddle, pituitary stalk visibility, and pituitary gland visibility were observed and recorded.

ADC maps were automatically generated after DWI. The ADCs of the solid part of the tumors were calculated from the original images. On a continuouslevel ADC map, the free-form marker tool was used to manually delineate each slice and measure ADCmean. Subsequently, the regions of interest (ROIs, size 10-20 $\mathrm{mm}^{2}$ ) were manually placed to cover solid tumor areas and avoid hemorrhagic or cystic lesions, with 6-8 ROIs per level, and ADCmax and ADCmin values were determined. Then, the averages of the ADCmax and ADCmin values of both neuroradiologists were calculated.

\section{Statistical analysis}

SPSS 23.0 software was used for statistical analysis. Chisquare test was used to compare the MRI characteristics (tumor variables). Two-sample $t$ tests were performed for the comparisons of age, maximal diameter, and ADC value. Then, variables were included in the multivariate logistic regression analysis. For all statistical analyses, a $P$ value less than 0.05 indicated a statistically significant difference. Differences between the ADC parameters calculated by the two radiologists were evaluated by the intraclass correlation (ICC) test. An ICC value of greater than 0.75 indicated excellent consistency, and average values were calculated. The receiver operating characteristic (ROC) curves and binary logistic regression analysis were used to differentiate between the diagnostic accuracy and optimal thresholds.

\section{Results}

\section{Patient clinical characteristics}

NFPMAs were diagnosed in 24 females and 36 males, whereas sellar meningiomas were diagnosed in 9 females and 43 males $(P<0.001)$. These findings indicating a statistically significant difference in the incidence between sexes. No significant differences were observed in terms of age between the two disease groups $(52.6 \pm 11.2$ vs $52.3 \pm 8.53$ years; $P=0.145$ ), as shown in Table 1 .

\section{MRI characteristics and ADC value analysis}

After univariate analysis, significant differences were observed in terms of T2W signals, enhancement features, hemorrhage/cysts/necrosis-related changes, sella enlargement, waist sign, depression of saddle, pituitary stalk visibility, and pituitary gland visibility between the NFPMA and sellar meningioma groups in routine MRI, all $P<0.05$. These two groups were similar in terms of the following parameters: maximal diameter, dural tail sign, DWI signal, and carotid artery encircling. Subsequently, the above nine significant MR features were reduced to five independent discrimination factors (including enhancement features, hemorrhage/cysts/necrosisrelated changes, depression of saddle, and pituitary gland visibility) by multivariate logistic regression analysis. The aforementioned data are presented in Table 1 . Typical MRIfeatures of these two tumors are shown in Supplementary Figs 1 and 2 (see section on supplementary materials given at the end of this article).

The ICCs were calculated to evaluate the agreement of the ADC parameters measured by two radiologists, and all values $>0.75$, reflecting good agreement. The ADCmax $\left(1.125 \pm 0.243\right.$ vs $\left.0.853 \pm 0.166 \times 10^{-3} \mathrm{~mm}^{2} / \mathrm{s}\right)$, ADCmean $\left(1.053 \pm 0.249\right.$ vs $\left.0.816 \pm 0.168 \times 10^{-3} \mathrm{~mm}^{2} / \mathrm{s}\right)$, and $\operatorname{ADCmin}\left(0.976 \pm 0.270\right.$ vs $\left.0.778 \pm 0.172 \times 10^{-3} \mathrm{~mm}^{2} / \mathrm{s}\right)$ values were significantly higher in the NFPMA group compared to the sellar meningioma group (all $P<0.001$ ), as shown in Table 2.

\section{ROC curve analysis}

As shown in ROC curve analyses (Table 3), the ADCmax indicated a relatively high discrimination ability with an AUC of 0.896 (95\% CI, 0.823-0.969), accuracy of $88.7 \%$, sensitivity of $82.7 \%$, and specificity of $93.30 \%$; an optimal cutoff value of $0.97 \times 10^{-3} \mathrm{~mm}^{2} / \mathrm{s}$ was used for discriminating NFPMAs from sellar meningiomas. For clinicoradiological

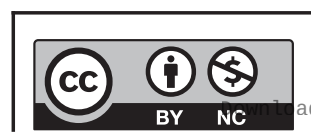

This work is licensed under a Creative Commons Attribution-NonCommercial 4.0 International License. ded from Bioscientifica.com at $04 / 26 / 2023$ 12:11:32PM 
Table 1 The clinical and magnetic resonance imaging features of non-functioning pituitary macroadenomas and sellar meningioma.

\begin{tabular}{l}
\hline Clinicoradiological features \\
\hline Age (years, mean \pm S.D.) \\
Sex (male/female) \\
Maximal diameter (cm) \\
T2W signal-high \\
Obvious enhancement feature \\
Hemorrhage/cysts/necrosis changes \\
DWI signal-high \\
Sella enlargement \\
Dural tail sign \\
Corset sign \\
Encircle carotid artery \\
Depression of saddle \\
Visibility of the pituitary stalk \\
Visibility of the pituitary gland \\
\hline
\end{tabular}

\begin{tabular}{|c|c|}
\hline $\begin{array}{c}\text { NFPMAs } \\
(n=60)\end{array}$ & $\begin{array}{c}\text { Sellar meningioma } \\
\qquad(n=52)\end{array}$ \\
\hline $\begin{array}{c}52.6 \pm 11.2 \\
36 / 24\end{array}$ & $\begin{array}{c}52.3 \pm 8.53 \\
9 / 43\end{array}$ \\
\hline $2.97 \pm 1.09$ & $3.18 \pm 1.21$ \\
\hline $50(83.3 \%)$ & 29 (55.8\%) \\
\hline 20 (33.3\%) & 41 (78.8\%) \\
\hline $42(70 \%)$ & $13(25 \%)$ \\
\hline $19(31.7 \%)$ & 18 (34.6\%) \\
\hline 55 (91.7\%) & 25 (48.1\%) \\
\hline $26(43.3 \%)$ & 32 (61.5\%) \\
\hline $28(46.7 \%)$ & $9(17.3 \%)$ \\
\hline $20(33.3 \%)$ & 14 (26.9\%) \\
\hline 49 (81.7\%) & 19 (36.5\%) \\
\hline $11(18.3 \%)$ & 21 (40.4\%) \\
\hline $3(5 \%)$ & 27 (51.9\%) \\
\hline
\end{tabular}

\begin{tabular}{c}
$\begin{array}{c}\text { Univariate } \\
\text { analysis }(P \text { value })\end{array}$ \\
\hline 0.145 \\
$0.001^{a}$ \\
0.347 \\
$0.001^{a}$ \\
$<0.001^{a}$ \\
$<0.001^{a}$ \\
0.151 \\
$<0.001^{a}$ \\
0.061 \\
$0.001^{a}$ \\
0.539 \\
$<0.001^{a}$ \\
$0.012^{a}$ \\
$<0.001^{a}$ \\
\hline
\end{tabular}

\begin{tabular}{c}
$\begin{array}{c}\text { Multivariate } \\
\text { analysis ( } P \text { value })\end{array}$ \\
\hline- \\
0.018 \\
- \\
- \\
0.006 \\
0.002 \\
- \\
- \\
- \\
- \\
- \\
0.016 \\
- \\
0.003
\end{tabular}

Odds ratio $(95 \% \mathrm{Cl})$ $4.482(1.300-15.454)$

$0.184(0.055-0.616)$ $6.846(2.029-23.092)$

A Student's $t$-test was used to compare the difference in age, while the chi-square test was used to compare the difference in other clinicoradiological features.

a $P<0.05$.

NFPMAs, non-functioning pituitary macroadenomas.

features, including sex, enhancement features, hemorrhage/ cysts/necrosis-related changes, depression of saddle, and pituitary gland visibility, a diagnostic efficacy was achieved with an AUC of 0.934 (95\% CI, 0.890-0.978), accuracy of $87.5 \%$, sensitivity of $88.5 \%$, and specificity of $81.7 \%$. Thus, on the combined use of ADCmax values and clinicoradiological features, the discrimination ability was improved to an AUC of 0.981 (95\% CI, 0.958-1.000), accuracy of $96.9 \%$, sensitivity of $95.6 \%$, and specificity of $94.2 \%$, which was indicative of the best identification ability and highest accuracy, as shown in Fig. 1.

\section{Discussion}

This was a preliminary study combining ADCmax and clinicoradiological features for the distinction between

Table 2 Comparison of ADCmax value, ADCmean value, and $A D C m i n$ value between non-functioning pituitary macroadenomas and sellar meningioma.

\begin{tabular}{|c|c|c|c|}
\hline $\begin{array}{l}\text { Parameter } \\
\left(\times 10^{-3} \mathrm{~mm}^{2} / \mathrm{s}\right)\end{array}$ & $\begin{array}{c}\text { NFPMAs } \\
(n=52)\end{array}$ & $\begin{array}{c}\text { Sellar } \\
\text { meningioma } \\
(n=45)\end{array}$ & $P$ value \\
\hline ADCmax value & $1.125 \pm 0.243$ & $0.853 \pm 0.166$ & $<0.001^{\circ}$ \\
\hline ADCmean value & $1.053 \pm 0.249$ & $0.816 \pm 0.168$ & $<0.001^{\circ}$ \\
\hline ADCmin value & $0.976 \pm 0.270$ & $0.778 \pm 0.172$ & $<0.001^{\circ}$ \\
\hline
\end{tabular}

A Student's $t$-test was used to compare the difference in ADC value. ap $<0.001$.

ADC, apparent diffusion coefficient; NFPMAs, non-functioning pituitary macroadenomas.
NFPMAs and sellar meningiomas, which were identified based on the MRI to date. In this study, we showed that the use of both ADCmax and clinicoradiological features had the best discrimination ability and highest sensitivity, and correctly identified the two tumors in $96 \%$ of all cases; therefore, this method can be applied to patients who underwent MRI before surgery.

In our study, sex was identified to be a significant factor in subgroup analysis. Females (82.69\%) were prone to develop meningiomas, and females accounted for $40 \%$ of NFPMA cases, which was similar to the results reported in previous studies $(8,22,23)$. The clinical manifestations of both tumors were similar, mainly showing reduced vision, blurred vision, headache, and dizziness.

MRI is the main examination method for intracranial tumors. Our present findings demonstrated significant differences in some MRI characteristics between NFPMAs and sellar meningiomas, which may be associated with their pathophysiological changes. In this study, the proportion of high signals in T2WI in NFPMAs was higher compared to that in sellar meningiomas, which may indicate that the former is more prone to hemorrhages, cysts, and necrosis-related changes (70\% in this study) than the latter. Most sellar meningiomas showed more obvious, uniform enhancement (78.8\% in this study), whereas most NFPMAs indicated heterogeneous, relatively poor enhancement, which was consistent with the results presented in previous studies $(8,24$, $25,26)$. We found that the proportion of NFPMAs with

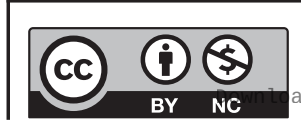

This work is licensed under a Creative Commons Attribution-NonCommercial 4.0 International License. ded from Bioscientifica,com at 04/26/2023 12:11:32PM 
Table 3 Diagnostic performance of different parameters for differentiating non-functioning pituitary macroadenomas from sellar meningioma.

\begin{tabular}{l} 
Observed parameters \\
\hline$A D C m a x$ \\
ADCmix \\
CDCmean \\
Clinicoradiological features \\
Clinicoradiological features and ADCmax
\end{tabular}

\begin{tabular}{c}
\hline AUC \\
\hline $0.896(0.823-0.969)$ \\
$0.787(0.789-0.947)$ \\
$0.868(0.692-0.883)$ \\
$0.934(0.890-0.978)$ \\
$0.981(0.958-1.000)$ \\
\hline
\end{tabular}

\begin{tabular}{c}
\hline ACC $(\%)$ \\
\hline 88.7 \\
80.4 \\
86.6 \\
87.5 \\
96.9 \\
\hline
\end{tabular}

\begin{tabular}{c}
\hline SEN $(\%)$ \\
\hline 82.7 \\
71.2 \\
84.6 \\
88.5 \\
95.6 \\
\hline
\end{tabular}

\begin{tabular}{c}
\hline SPE $(\%)$ \\
\hline 93.3 \\
88.9 \\
86.7 \\
81.7 \\
94.2 \\
\hline
\end{tabular}

\begin{tabular}{c}
\hline Cut off \\
\hline $0.97\left(\times 10^{-3} \mathrm{~mm}^{2} / \mathrm{s}\right)$ \\
$0.86\left(\times 10^{-3} \mathrm{~mm}^{2} / \mathrm{s}\right)$ \\
$0.89\left(\times 10^{-3} \mathrm{~mm}^{2} / \mathrm{s}\right)$ \\
0.3108 \\
0.5103
\end{tabular}

ACC, accuracy; AUC, area under receiver operating characteristic curve; NFPMAs, nonfunctioning pituitary macroadenomas; SEN, sensitivity; SPE, specificity.

waist signs was significantly higher compared to that of sellar meningiomas, which may be closely associated with the soft texture of NFPMAs. The tumor is blocked when growing through the saddle septum, which leads to waist signs; however, sellar meningiomas are firm in
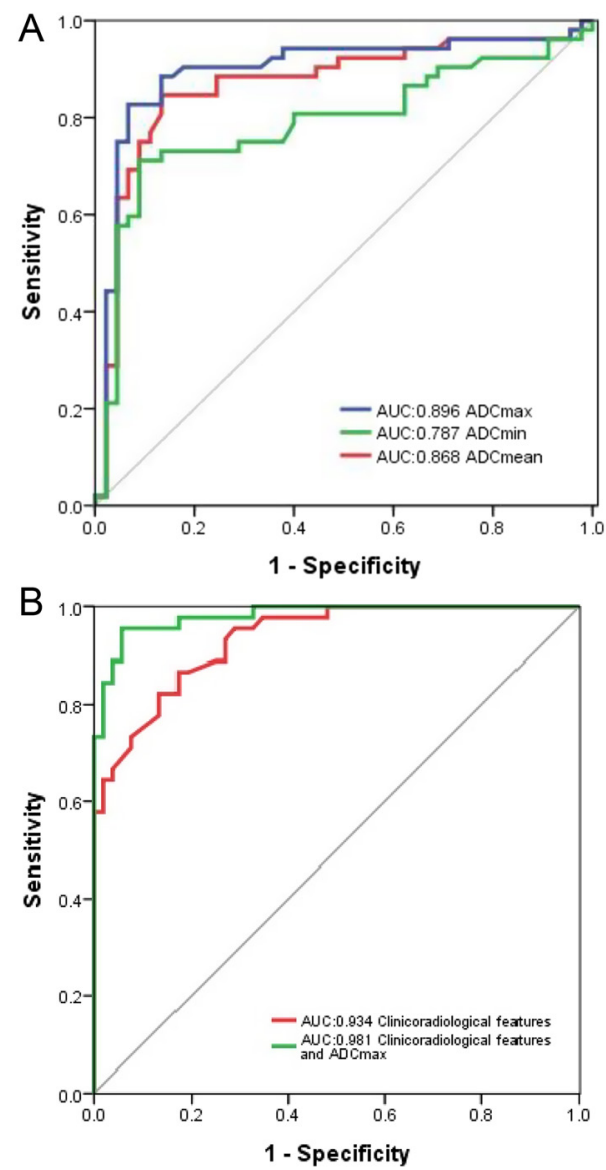

\section{Figure 1}

(A) ADCmax, ADCmean, and ADCmin values for differential diagnosis of non-functioning pituitary macroadenomas and sellar meningiomas. Compared with $A D C$ mean and $A D C m i n$ values, $A D C$ max value demonstrated a relatively high discriminating ability, with an AUC of 0.896. (B) Compared with the clinicoradiological features alone, combining ADCmax and clinicoradiological features indicated the best identification ability, with an improved AUC of 0.981. ADC, apparent diffusion coefficient. texture. Furthermore, sella enlargement, depression of saddle, and non-visibility of the pituitary stalk and gland were more commonly encountered in NFPMAs. Together, these features proved the different origins and growth patterns of the two tumors. Sellar meningiomas (except those arising from the dura surrounding the pituitary fossa) first grow above the saddle, then break through the saddle septum and extend downward the saddle. However, NFPMAs first grow in the saddle, spherically enlarging the saddle, cause depression of saddle, and then break through the saddle septum, thereby extending onto the saddle. The aforementioned features showed a strong association with the identification of these two tumors and can be selected to be as predictive factors.

DWI has evolved as a functional MRI modality that utilizes the changes in water molecule diffusion motion to provide information about the tumor microenvironment (27). No statistical differences in DWI signals were observed between these two tumors, which may be because there are many factors affecting the DWI signals. These factors mainly include diffusion sensitivity coefficient (b) and T2 penetration effect, particularly airtissue interface artifacts from the skull base in our study, among others (28). ADC provides important additional information beyond that provided by MRI $(18,29)$. The main advantage of using ADC is its ability to extract quantitative information and enable assessment of viable cellularity $(28,30)$. In this study, we observed that the ADC values were significantly higher in NFPMAs compared to in sellar meningiomas $(P<0.001)$, and ADCmax indicated a relatively higher discrimination ability than ADCmin and ADCmean, with an AUC of 0.896 (optimal cutoff value, $0.97 \times 10^{-3} \mathrm{~mm}^{2} / \mathrm{s}$ ) for distinguishing NFPMAs from sellar meningiomas. These findings, agreed with previously published reports (31), and are possibly due to the wider range of ADC values in pituitary adenomas that tend to be non-homogeneous compared to homogeneous meningiomas. Although low ADC values indicated restricted diffusion of water

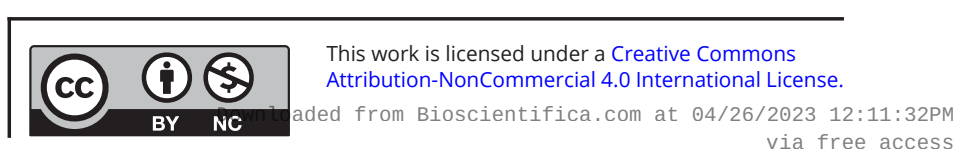


identified in meningiomas, some authors have reported that the ADC of pituitary adenomas was not significantly different from that of menigiomas $(32,33)$. This may be related to the small sample size of studies reported in the past.

After analyzing the ADC values, we found that it may be associated with the ratio of extracellular and intracellular gaps and the different cell types (34). NFPMAs demonstrated fibrous tissue hyperplasia and loosely arranged cells, sellar meningioma cells were closely connected by intercellular cell junctions, with increased intracellular complex protein molecules, and intercellular areas are packed by numerous cytoplasmic processes $(34,35)$. Therefore, compared with NFPMA cells, sellar meningioma cells may have more intracellular space and less extracellular space, thereby limiting the diffusion of water. The reason for different ADC values may be explained based on these histological differences.

ADCmax and clinicoradiological features together performed better than ADCmax and clinicoradiological features alone, resulting in an AUC of 0.981, accuracy of $96.9 \%$, sensitivity of $95.6 \%$, and specificity of $94.2 \%$, and significantly improved the identification ability between NFPMAs and sellar meningiomas. The results showed that ADC combined with clinicoradiological features, as a noninvasive method, provided more diagnostic information, thereby aiding in the accurate diagnosis of these two tumors before surgery and help in selecting an appropriate surgical plan.

This study has several limitations. First, sellar and parasellar lesions tend to cause limitations in ADC value measurement because of susceptibility artifacts, such as air-tissue interface artifacts. Second, this is a singlecenter study, and multi-center studies will be needed to further validate the results. Finally, multimodal MRI techniques such as perfusion-weighted imaging (PWI) and susceptibility-weighted imaging (SWI), were not included in this study and will have to be explored in the future.

\section{Conclusion}

In conclusion, ADCmax values and clinicoradiological features are useful for distinguishing NFPMAs from sellar meningioma. Moreover, combining ADCmax and clinicoradiological features may further improve this discrimination ability.

\section{Supplementary materials}

This is linked to the online version of the paper at https://doi.org/10.1530/ EC-20-0434

\section{Declaration of interest}

The authors declare that there is no conflict of interest that could be perceived as prejudicing the impartiality of the research reported.

\section{Funding}

This study was supported by grants from the National Natural Science Foundation of China (81772006), Lanzhou University Second Hospital 'Cuiying Technology Innovation Plan' Applied Basic Research Project (CY2017-MS03), and special fund project for doctoral training program of Lanzhou University Second Hospital (grant numbers YJS-BD-33).

\section{Acknowledgement}

The authors would like to thank MogoEdit for English language editing

\section{References}

1 Zhu H, Miao Y, Shen Y, Guo J, Xie W, Zhao S, Dong W, Zhang Y \& Li C. The clinical characteristics and molecular mechanism of pituitary adenoma associated with meningioma. Journal of Translational Medicine 201917 354. (https://doi.org/10.1186/s12967019-2103-0)

2 Imber BS, Lin AL, Zhang Z, Keshavamurthy KN, Deipolyi AR, Beal K, Cohen MA, Tabar V, DeAngelis LM, Geer EB, et al. Comparison of radiographic approaches to assess treatment response in pituitary adenomas: is RECIST or RANO good enough? Journal of the Endocrine Society 20193 1693-1706. (https://doi. org/10.1210/js.2019-00130)

3 Rieken S, Habermehl D, Welzel T, Mohr A, Lindel K, Debus J \& Combs SE. Long term toxicity and prognostic factors of radiation therapy for secreting and non-secreting pituitary adenomas. Radiation Oncology 20138 18. (https://doi.org/10.1186/1748717X-8-18)

4 Ntali G \& Wass JA. Epidemiology, clinical presentation and diagnosis of non-functioning pituitary adenomas. Pituitary 201821 111-118. (https://doi.org/10.1007/s11102-018-0869-3)

5 Bang M, Suh JH, Park JB \& Weon YC. Pure intrasellar meningioma mimicking pituitary macroadenoma: magnetic resonance imaging and review of the literature. World Neurosurgery $201691675 . e 1-675$ e4. (https://doi.org/10.1016/j.wneu.2016.04.063)

6 Ajlan AM, Choudhri O, Hwang P \& Harsh G. Meningiomas of the tuberculum and diaphragma sellae. Journal of Neurological Surgery: Part B, Skull Base 201576 74-79. (https://doi. org/10.1055/s-0034-1390400)

7 Famini P, Maya MM \& Melmed S. Pituitary magnetic resonance imaging for sellar and parasellar masses: ten-year experience in 2598 patients. Journal of Clinical Endocrinology and Metabolism 201196 1633-1641. (https://doi.org/10.1210/jc.2011-0168)

8 Cappabianca P, Cirillo S, Alfieri A, D'Amico A, Maiuri F, Mariniello G, Caranci F \& de Divitiis E. Pituitary macroadenoma and diaphragma sellae meningioma: differential diagnosis on MRI. Neuroradiology 199941 22-26. (https://doi.org/10.1007/s002340050698)

9 Dzhindzhikhadze RS, Dreval ON, Lazarev VA, Polyakov AV, Kambiev RL \& Salyamova EI. Transpalpebral approach for microsurgical removal of tuberculum sellae meningiomas. Asian Journal of Neurosurgery 202015 98-106. (https://doi.org/10.4103/ajns. AJNS_186_19)

10 Hassan HA, Bessar MA, Herzallah IR, Laury AM, Arnaout MM \& Basha MAA. Diagnostic value of early postoperative MRI and diffusion-weighted imaging following trans-sphenoidal resection of non-functioning pituitary macroadenomas. Clinical Radiology 2018 73 535-541. (https://doi.org/10.1016/j.crad.2017.12.007)

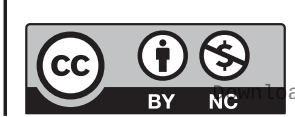

This work is licensed under a Creative Commons Attribution-NonCommercial 4.0 International License. ded from Bioscientifica com at 04/26/2023 12:11:32PM 
11 Mahvash M, Igressa A, Pechlivanis I, Weber F \& Charalampaki P. Endoscopic endonasal transsphenoidal approach for resection of a coexistent pituitary macroadenoma and a tuberculum sellae meningioma. Asian Journal of Neurosurgery 20149 236. (https://doi org/10.4103/1793-5482.146629)

12 Wu LM, Li YL, Yin YH, Hou GQ, Zhu R, Hua XL, Xu JR \& Chen ZA. Usefulness of dual-energy computed tomography imaging in the differential diagnosis of sellar meningiomas and pituitary adenomas: preliminary report. PLOS ONE 20149 e90658. (https://doi. org/10.1371/journal.pone.0090658)

13 Gatto F, Perez-Rivas LG, Olarescu NC, Khandeva P, Chachlaki K, Trivellin G, Gahete MD, Cuny T \& on behalf of the ENEA Young Researchers Committee (EYRC). Diagnosis and treatment of parasellar lesions. Neuroendocrinology 2020110 728-739. (https://doi. org/10.1159/000506905)

14 Rutland JW, Loewenstern J, Ranti D, Tsankova NM, Bellaire CP, Bederson JB, Delman BN, Shrivastava RK \& Balchandani P. Analysis of 7-tesla diffusion-weighted imaging in the prediction of pituitary macroadenoma consistency. Journal of Neurosurgery 2020 [epub]. (https://doi.org/10.3171/2019.12.JNS192940)

15 Xiaoai K, Qing Z, Lei H \& Junlin Z. Differentiating microcystic meningioma from atypical meningioma using diffusion-weighted imaging. Neuroradiology 202062 601-607. (https://doi.org/10.1007/ s00234-020-02374-3)

16 Sohu DM, Sohail S \& Shaikh R. Diagnostic accuracy of diffusion weighted MRI in differentiating benign and malignant meningiomas. Pakistan Journal of Medical Sciences 201935 726-730. (https://doi. org/10.12669/pjms.35.3.1011)

17 Padhani AR, Koh DM \& Collins DJ. Whole-body diffusion-weighted MR imaging in cancer: current status and research directions. Radiology 2011261 700-718. (https://doi.org/10.1148/radiol.11110474)

18 Ogiwara H, Tsutsumi Y, Matsuoka K, Kiyotani C, Terashima K \& Morota N. Apparent diffusion coefficient of intracranial germ cell tumors. Journal of Neuro-Oncology 2015121 565-571. (https://doi. org/10.1007/s11060-014-1668-y)

19 Chen T, Jiang B, Zheng Y, She D, Zhang H, Xing Z \& Cao D. Differentiating intracranial solitary fibrous tumor/ hemangiopericytoma from meningioma using diffusion-weighted imaging and susceptibility-weighted imaging. Neuroradiology $20206 \mathbf{6 2}$ 175-184. (https://doi.org/10.1007/s00234-019-02307-9)

20 He W, Xiao X, Li X, Guo Y, Guo L, Liu X, Xu Y, Zhou J \& Wu Y. Whole-tumor histogram analysis of apparent diffusion coefficient in differentiating intracranial solitary fibrous tumor/ hemangiopericytoma from angiomatous meningioma. European Journal of Radiology 2019112 186-191. (https://doi.org/10.1016/j. ejrad.2019.01.023)

21 Surov A, Ginat DT, Sanverdi E, Lim CCT, Hakyemez B, Yogi A, Cabada $\mathrm{T} \&$ Wienke A. Use of diffusion weighted imaging in differentiating Between maligant and benign meningiomas. A multicenter analysis. World Neurosurgery 201688 598-602. (https:// doi.org/10.1016/j.wneu.2015.10.049)

22 Najmaldin A, Malek M, Madani NH, Ghorbani M, Akbari H, Khajavi A, Qadikolaei OA \& Khamseh ME. Non-functioning pituitary macroadenoma: surgical outcomes, tumor regrowth, and alterations in pituitary function - 3-year experience from the Iranian Pituitary Tumor Registry. Hormones 201918 197-205. (https://doi. org/10.1007/s42000-019-00109-5)
23 Ajler P, Campero A, Hem S, Goldschmidt E, Landriel F, Carrizo A \& Yampolsky C. Cirugía transnasal endoscópica para tumores de hipófisis. Surgical Neurology International 20123 389. (https://doi. org/10.4103/2152-7806.104403)

24 Pinzer T, Krishnan KG \& Schackert G. The diaphragma sellae meningioma - a rare differential diagnosis of non-functioning pituitary adenoma. Zentralblatt für Neurochirurgie 200465 195-197. (https://doi.org/10.1055/s-2004-822785)

25 Michael AS \& Paige ML. MR imaging of intrasellar meningiomas simulating pituitary adenomas. Journal of Computer Assisted Tomography 198812 944-946. (https://doi.org/10.1097/00004728198811000-00007)

26 Abe T, Matsumoto K, Homma H, Kawamura N, Iwata T \& Nemoto S. Dorsum sellae meningioma mimicking pituitary macroadenoma: case report. Surgical Neurology 199951 543-546; discussion 546. (https://doi.org/10.1016/s0090-3019(99)00007-5)

27 Panyaping T, Taebunpakul P \& Tritanon O. Accuracy of apparent diffusion coefficient values and magnetic resonance imaging in differentiating suprasellar germinomas from chiasmatic/ hypothalamic gliomas. Neuroradiology Journal 202033 201-209. (https://doi.org/10.1177/1971400920912656)

28 Giordano M, Samii A, Samii M \& Nabavi A. Magnetic resonance imaging-apparent diffusion coefficient assessment of vestibular schwannomas: systematic approach, methodology, and pitfalls. World Neurosurgery 2019125 e820-e823. (https://doi.org/10.1016/j. wneu.2019.01.176)

29 Elbir ŞF, Ozturk M \& Dogan S. The ability and utility of diffusionweighted magnetic resonance imaging with different ' $b$ ' values in the differentiation of benign from malignant lung lesions. Polish Journal of Radiology 202085 e14-e20. (https://doi.org/10.5114/pjr.2020.92834)

30 Park JE, Kim HS, Park SY, Jung SC, Kim JH \& Heo HY. Identification of early response to anti-angiogenic therapy in recurrent glioblastoma: amide proton transfer-weighted and perfusionweighted MRI compared with diffusion-weighted MRI. Radiology 2020295 397-406. (https://doi.org/10.1148/radiol.2020191376)

31 Mahmoud OM, Tominaga A, Amatya VJ, Ohtaki M, Sugiyama K, Saito T, Sakoguchi T, Kinoshita Y, Shrestha P, Abe N, et al. Role of PROPELLER diffusion weighted imaging and apparent diffusion coefficient in the diagnosis of sellar and parasellar lesions. European Journal of Radiology 201074 420-427. (https://doi.org/10.1016/j. ejrad.2009.03.031)

32 Yamasaki F, Kurisu K, Satoh K, Arita K, Sugiyama K, Ohtaki M, Takaba J, Tominaga A, Hanaya R, Yoshioka H, et al. Apparent diffusion coefficient of human brain tumors at MR imaging. Radiology 2005235 985-991. (https://doi.org/10.1148/radiol.2353031338)

33 Sutherland-Smith J, King R, Faissler D, Ruthazer R \& Sato A. Magnetic resonance imaging apparent diffusion coefficients for histologically confirmed intracranial lesions in dogs. Veterinary Radiology and Ultrasound 201152 142-148. (https://doi.org/10.1111/j.17408261.2010.01764.x)

34 Shankar JJS, Hodgson L \& Sinha N. Diffusion weighted imaging may help differentiate intracranial hemangiopericytoma from meningioma. Journal of Neuroradiology 201946 263-267. (https://doi. org/10.1016/j.neurad.2018.11.002)

35 Jaskolski D, Papierz T, Liberski PP \& Sikorska B. Ultrastructure of meningiomas: autophagy is involved in the pathogenesis of 'intranuclear vacuoles'. Folia Neuropathologica 201250 187-193.

Received in final form 14 October 2020

Accepted 19 October 2020

Accepted Manuscript published online 19 October 2020 https://ec.bioscientifica.com https://doi.org/10.1530/EC-20-0434 (c) 2020 The authors Published by Bioscientifica Ltd

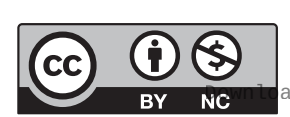

This work is licensed under a Creative Commons Attribution-NonCommercial 4.0 International License. ded from Bioscientifica com at 04/26/2023 12:11:32PM 